\title{
An overall view of the process of the regulation of human iron metabolism
}

\author{
Dorota Formanowicz $^{1 *}$, Piotr Formanowicz ${ }^{2,3}$ \\ ${ }^{1}$ Department of Clinical Biochemistry and Laboratory Medicine, Poznań University of Medical Sciences, Poznań, Poland \\ ${ }^{2}$ Institute of Computing Science, Poznań University of Technology, Poznań, Poland \\ ${ }^{3}$ Institute of Bioorganic Chemistry, Polish Academy of Sciences, Poznań, Poland \\ * Corresponding author: doforman@ump.edu.pl
}

\begin{abstract}
Iron is a key component of many reactions in the human body, and by virtue of its ability to accept and donate electrons, it is required for a variety of normal cellular functions and is vital for proper growth and development. However, natural iron is rather insoluble and excess of iron is harmful since it can catalyze the formation of oxygen radicals. Fortunately, there are also mechanisms for protecting human body from excess 'free' iron. This is particularly important, given the fact that humans have very limited capacity to excrete iron. Therefore, cells have developed mechanisms to improve the solubility of iron to control intracellular iron concentrations at the point of iron absorption in the small intestine and other tissues. Since the described process is highly complex, a profound understanding of all the relationships occurring among its components is possible when a systems approach is applied to its analysis.
\end{abstract}

Key words: iron, homeostasis, transferrin, hepcidin, formal models

\section{Introduction}

In order to understand how human organism is able to maintain iron homeostasis, it is essential to consider the movement of iron between various compartments of the body. Under normal conditions, approximately 1-2 mg of iron per day enters the body via the cells of the proximal small intestine. This newly absorbed dietary iron is released into the bloodstream and binds to the serum transferrin (Tf). Approximately $3 \mathrm{mg}$ of iron circulates bind to this protein, and as compared with $4 \mathrm{~g}$ of total body iron, it is a small portion. Iron ions bound to Tf are taken up by cells via transferrin receptor-1 (TfR1)-mediated endocytosis (Huebers and Finch, 1987). Most of this iron is taken up by the developing erythrocytes of the bone marrow and is used in the production of hemoglobin at a rate of approximately $22 \mathrm{mg}$ of iron per day (Anderson et al., 2007). About $65-70 \%$ of total body iron exists in this form. Thereafter, old or damaged red blood cells are removed from the bloodstream by macrophages of the reticulo-endothelial system and iron is recycled back to plasma Tf. The total iron content of Tf corresponds to less than $0.1 \%$ of the body iron, but it is highly dynamic.
Iron can be used to synthesize many proteins, such as cytochromes containing heme, and proteins containing iron-sulfur (Fe-S) clusters. Approximately 10-15\% of body iron is present in such proteins, with up to $80 \%$ of it found in muscle cell myoglobin. The remaining $20 \%$ of body iron is present as the storage iron, predominantly located in the macrophages of the reticulo-endothelial system and the hepatocytes of the liver (Anderson et al., 2007). The movement of iron in the human organism is a tightly regulated process, which can be modulated according to the iron requirements.

The recent advancements in the knowledge of the regulation of iron metabolism have made it possible to understand better the pathophysiology of some human disorders. The aim of this work was to present the current state of knowledge of the regulation of the human systemic iron homeostasis, without focusing on the diseases derived from the disturbances of this process.

\section{Iron absorption in the duodenum}

In most conditions, dietary iron is a critical determinant of the body's iron status because once absorbed 
it is not actively excreted (Wang and Pantopoulos, 2011). Iron absorption by enterocytes is programmed to match the body needs. There are two major signals that affect iron absorption. One of them reflects the need for iron due to erythropoiesis (red blood cells generation). The hormone erythropoietin (EPO), produced by the kidneys, stimulates red blood cells production, and can act directly on intestinal epithelial cells to increase dietary iron absorption for subsequent utilisation in the bone marrow. Until recently, it was believed that EPO is not a signal regulating the iron absorption. However, recent research has provided a novel insight into the mechanisms by which the body senses and responds to the changes in the erythroid requirements for iron (Chung et al., 2009).

Another signal depends on the amount of iron in body iron storages. If the level of body iron storage is low, iron absorption is stimulated. Such signal (and some others) regulates the iron absorption in the proximal duodenum, where the iron is absorbed.

The form of iron which is presented to the digestive tract affects iron absorption, and inorganic iron ions change the oxidation state during the absorption process. There are two forms of dietary iron, i.e. non-heme iron (ferric, $\mathrm{Fe}^{3+}$ ) and heme iron (ferrous, $\mathrm{Fe}^{2+}$ ) (Formanowicz et al., 2007).

\section{Non-heme iron absorption}

Non-heme iron is released by acid digestion in the stomach and must be reduced to the ferrous ion by reductases, prior to the uptake by duodenal enterocytes (intestinal epithelial cells responsible for nutrient absorption) (Theurl et al., 2005). Two ferric reductases are involved in this process: duodenal cytochrome $b$ (DCYTB) and cytochrome $b$ reductase- 1 (CYBRD-1). Ferrous ions are transported across the enterocyte apical membrane by divalent metal transporter-1 (DMT-1) (Gunshin et al., 1997), a member of the solute carrier group (SLC) of membrane transport proteins. This transport protein is also known as a solute carrier family 11 , member 2 (SLC11A2), natural resistance-associated macrophage protein-2 (Nramp2) or divalent cation transporter-1 (DCT-1), acting as a proton coupled divalent ion transporter. The amount of DMT-1 in the apical membrane is regulated by the body iron requirements. DMT-1 transport is $\mathrm{pH}$ dependent, optimal at acidic $\mathrm{pH}$ (5.5 to 6.0), electrogenic, and associated with the proton co-transport
(Gunshin et al., 1997). Alternative splicing of the DMT-1 gene produces two isoforms distinguished by the presence (isoform I) or absence (isoform II) of an iron-responsive element (IRE) in the $3^{\prime}$ untranslated region (UTR), both being competent in the iron transport. DMT-1 synthesis is reduced in iron-enriched diets but increases when the iron intake is restricted (CanonneHergaux et al., 1999). The converse is true for the liver, since this organ acts as a reservoir of iron. High levels of dietary iron lead to an increase in DMT-1 synthesis in hepatocytes, promoting iron acquisition, whereas low levels lead to a decrease in hepatic DMT-1synthesis, thus causing a reduction in iron accumulation (Trinder et al., 2000). Although kidneys are not usually associated with the serum iron balance, several studies have found renal DMT-1 accumulation in mice and rats, which suggest that this organ may play a role in iron homeostasis (Ferguson et al., 2001; Veuthey et al., 2008). Recently it has been found that the suppression of SLC11A2 expression is essential for maintaining duodenal integrity during the dietary iron overload (Shirase et al., 2010). Studies in the animals carrying missense mutations in SLC11A2 have demonstrated two major roles for this transporter, i. e. the intestinal non-heme iron transport and the iron uptake (Gunshin et al., 2005). SLC11A2 has also been found in Tf cycle endosomes in erythroid precursors (Canonne-Hergaux et al., 2001), where it may participate in transfer of iron to the cytoplasm. Moreover, SLC11A2 was also revealed in hepatocytes, where it has been postulated to be involved in non-Tf - bound iron uptake (Trinder et al., 2000) and in the placenta, where it may participate in the materno-fetal iron transfer (Georgieff et al., 2000). After entering the cytoplasm of the intestinal cells, ferrous iron joins the cytosolic labile iron pool (LIP) and is finally exported across the enterocyte's basolateral membrane to the circulation via ferroportin-1 (FPN-1). The absorbed iron may be stored bound to ferritin within the enterocyte, and is later lost when the intestinal mucosa is sloughed. The accumulation of iron will be discussed in Section: Iron distribution.

\section{Heme iron absorption}

The dietary heme iron absorption pathway is distinct from that of non-heme iron absorption (Wyllie and Kaufman, 1982). Heme iron, ingested as myoglobin and hemoglobin, is the most easily absorbed form. In the presence 
of gastric acid, the globin molecule is split off and ferrous iron is liberated and transported with its phosphorin ring from the stomach into the duodenum and jejunum. The mechanisms of absorption and uptake of heme by enterocytes and cultured cells have been studied for a long time. Currently, there are two prevailing hypotheses explaining the mechanisms of that process.

Firstly, there is a hypothesis that heme is taken up by receptor-mediated endocytosis (RME). The internalized heme is degraded by heme oxygenase-2 (HO-2) inside the endosomal vesicles, releasing non-heme iron and generating biliverdin. The non-heme iron is then transported to the cytoplasm by DMT-1 (West and Oates, 2008), joins the LIP, and is finally transported to the bloodstream by FPN-1.

Secondly, heme-iron may also be taken up directly into the cytoplasm by a recently discovered heme transporter-heme carrier protein-1 (HCP-1) (Shayeghi et al., 2005). The role of HCP-1 in heme/iron biology was later overshadowed by the finding that HCP-1 primarily functions as an intestinal proton-coupled folate transporter (PCFT) (Inoue et al., 2008). HCP-1 mRNA synthesis appears to be less responsive to iron deficiency (LatundaDada et al., 2006) when compared to the non-heme importer - DMT-1 mRNA synthesis (Sharp et al., 2002). It is worth mentioning that studies regarding the full physiological role of PCFT/HCP-1 in the heme metabolism are still going on. The researchers propose that PCFT/HCP-1 functions in endosomes to export heme which is released from hemoglobin:haptoglobin ( $\mathrm{Hb}: \mathrm{Hp}$ ) complexes into the cytosol for degradation by microsomal heme oxygenase (HO) (Schaer et al., 2008). Heme, after entering the cytoplasm, is taken by PCFT/HCP-1, and may be catabolized to non-heme iron and biliverdin by an inducible microsomal enzyme - heme oxygenase-1 (HO-1), located in the endoplasmic reticulum. It allows heme iron to enter the same LIP as non-heme iron. The synthesis and function of PCFT/HCP-1 are shown to be adaptive to the rate of heme degradation by HO-1 (Latunda-Dada et al., 2006). Alternatively, intact heme, instead of being catabolized by HO-1, may be transported directly to the bloodstream by the recently discovered heme transporter called feline leukemia virus, subgroup C receptor (FLVCR) (Quigley et al., 2004). This transport requires an extracellular heme-binding protein such as albumin or circulating hemopexin (HPX) since export is not observed in the absence of a carrier protein (Yang et al., 2010). HPX is present in the circulation at levels similar to that of the $\mathrm{Tf}$ - iron transporter, suggesting that the systemic circulation of heme bound to HPX (or the more abundant plasma protein albumin) may be of relevance to iron homeostasis (Khan and Quigley, 2011). The presence of FLVCR in macrophages responsible for the processing of senescent erythrocytes was also detected. It was found that iron derived from heme catabolism is either exported by the phagocytic cell-specific divalent metal transporter - natural resistance-associated macrophage protein-1 (Nramp-1) (Soe-Lin et al., 2009) and FPN-1, or stored within ferritin. However, during erythrocytophagocytosis, not all the hemes appear to be broken down by HO-1 (Knutson et al., 2005), and FLVCR provides an important heme iron-export function that impacts the systemic iron homeostasis (Keel et al., 2008).

Heme transport research is still ongoing and new proteins are analyzed in this respect. Recently, the role of the mitochondrial ATP binding cassette transporters, such as ATP-binding cassette sub-family B member 6, 7, 10 ( $\mathrm{ABCB} 6, \mathrm{ABCB} 7, \mathrm{ABCB} 10$, respectively), in transport of heme biosynthesis intermediates has been studied. ABCB7 - appears to be important for cytosolic but not mitochondrial $\mathrm{Fe}-\mathrm{S}$ cluster biogenesis. Both $\mathrm{ABCB} 6$ and $\mathrm{ABCB} 10$ are proteins consistently co-expressed with heme synthesis pathway enzymes, suggesting a role for these proteins in heme metabolism. A physiological substrate of $\mathrm{ABCB} 6$, relevant to heme synthesis, has yet to be identified. Another protein - ATP-binding cassette sub-family $\mathrm{G}$ member 2 (ABCG2) also known as mitoxantrone resistance protein, breast cancer resistance protein, and placenta-specific $\mathrm{ABC}$ transporter (MXR, $\mathrm{BCRP}$, and $\mathrm{ABCP}$ respectively) located in plasma membrane are found to be potentially responsible for heme exports (Khan and Quigley, 2011).

Although in the last few years, the knowledge of the heme physiology has increased vastly, the fundamental questions still remain unanswered. They include the identity of transporters involved in the transfer of heme and heme intermediates across the mitochondrial membranes, the sites of heme transfer to apoproteins, the identity of intracellular heme chaperones, the comparative contributions of FLVCR and the HO system to cellular protection from oxidative stress and/or heme excess, and the role of the systemic circulation of heme in iron homeostasis and its other functions (Khan and Quigley, 2011). 


\section{INTESTINAL LUMEN}

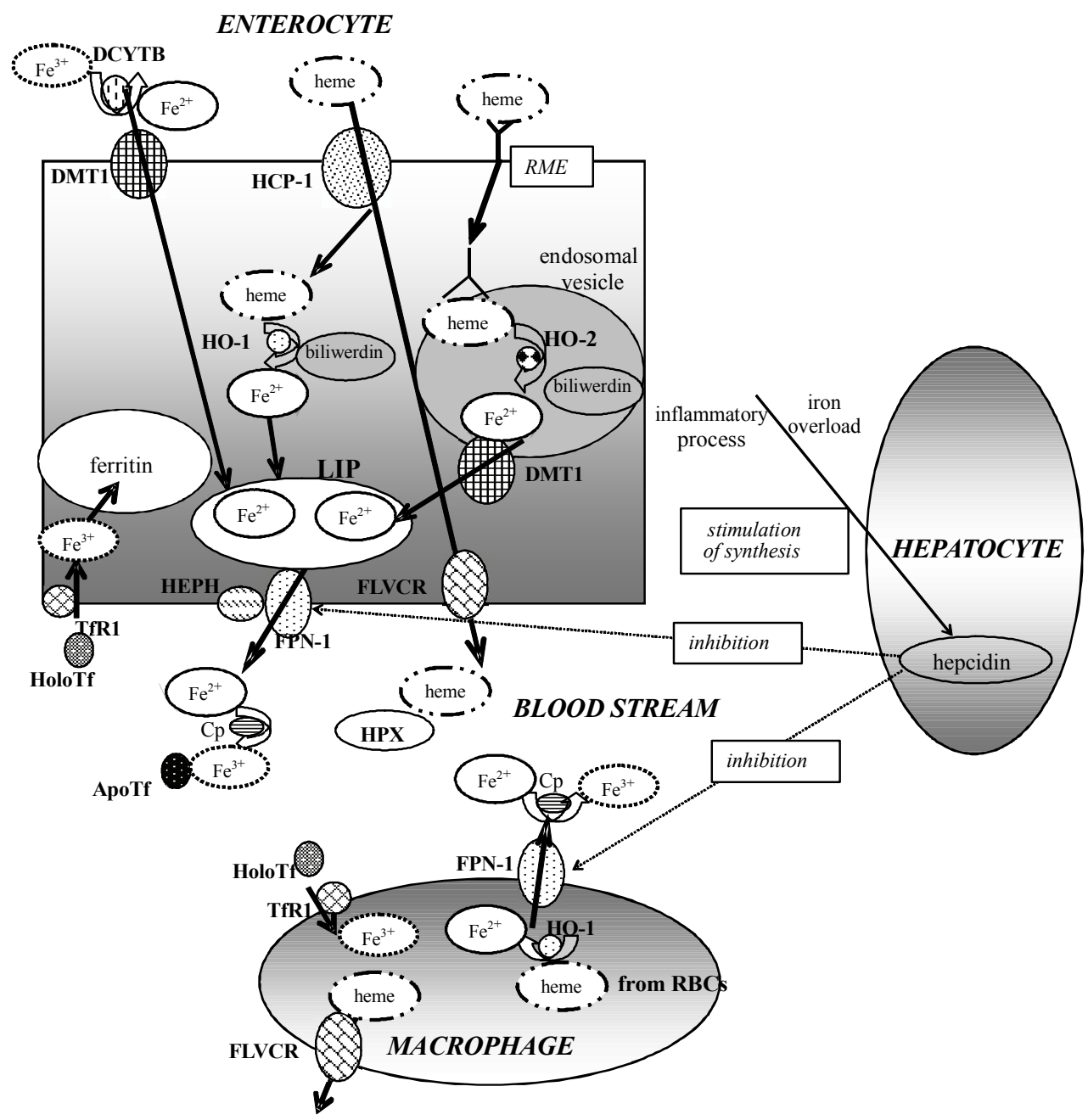

Fig. 1. Schematic diagram (not to scale) showing the regulation of iron efflux from enterocytes and macrophages (based on Wang J. and Pantopoulos K., 2011)

Enterocytes absorb iron from the diet and macrophages phagocytose iron-loaded senescent red blood cells, or acquire iron by other mechanisms. Both cell types release $\mathrm{Fe}^{2+}$ into the plasma via ferroportin -1 (FPN-1), which is incorporated into ApoTf following oxidation to $\mathrm{Fe}^{3+}$ via hephaestin (HEPH) or ceruloplasmin $(\mathrm{Cp})$. Hepatocytes generate hepcidin hormone in response to high iron or inflammatory signals, which inhibits the efflux of iron via Fpn and promotes its retention within enterocytes and macrophages.

A schematic diagram showing the regulation of iron efflux from enterocytes and macrophages, based on the current knowledge, has been presented in Figure 1.

\section{Ferroportin - hepcidin axis determinates plasma iron concentration}

\section{Ferroportin - an iron exporter}

Iron efflux from the enterocyte basolateral membrane is performed by membrane-bound ferrous iron transporter - FPN-1, also known as iron-regulated transporter-1 (IREG-1), metal transporter protein-1 (MTP-1) or the product of solute carrier family 40 , member 1 gene
(SCL40A1) (Donovan A. et al., 2000) previously called as solute carrier family 11 , member 3 gene (SCL11A3). This protein has been independently identified by three groups of researchers who used different approaches (Abboud and Haile, 2000; Donovan et al., 2000; McKie et al., 2000). FPN-1 is synthesized in many iron-exporting cells, including hepatocytes, macrophages - where FPN-1 exports iron from the cytosol into the bloodstream (for iron recycling), and placental syncytiotrophoblasts. Thus, it not only plays a fundamental role in the release of iron from tissues, but also in maternal iron transfer to the fetus (Donovan et al., 2005; McKie and 
Barlow, 2004). There is evidence that FPN-1 is also synthesized in renal cells located in the glomerulus and proximal tubular cells of this tissue but its role remains obscure (Wolff et al., 2011).

The FPN-mediated efflux of $\mathrm{Fe}^{2+}$ from enterocytes and macrophages, which is responsible for clearing senescent red blood cells into the plasma, is critical for the systemic iron homoeostasis. Afterwards, iron is oxidized by a membrane bound ferroxidase - hephaestin (HEPH), that physically interacts with FPN-1 yielding ferric ions that are then bound by plasma Tf and distributed around the body via blood (Theurl et al., 2005; Yeh et al., 2009). It should also be noted that $\mathrm{Fe}^{3+}$ transported by FPN-1 must first be reduced by a ceruloplasmin $(\mathrm{Cp})$ homologue - hephaestin (HEPH) (Vulpe et al., 1999), mostly synthesized in the small intestine and colon, to be prepared for Tf transport. So, the rate of absorption of iron by enterocytes in the human organism, a key regulation point of systemic iron metabolism, is controlled by the activity of the two membrane transporters, i.e. DMT-1 and FPN-1. A very interesting and still poorly understood issue is the regulation of $F P N-1$ expression. It is regulated at several levels (Zhang et al., 2009), including transcriptional regulation in the duodenal mucosa and macrophages (McKie et al., 2000; Knutson et al., 2003), translational regulation by the iron-regulatory element/iron-regulatory protein (IRE/IRP) system (McKie et al., 2000; Abboud and Haile, 2000; Lymboussaki et al., 2003), and post-translational regulation by hepcidin, secreted by hepatocytes in response to increased iron abundance (Park et al., 2001; Pigeon et al., 2001). Hepcidin, a major regulator of iron metabolism, binds to FPN-1 in tissue culture cells, resulting in internalization and degradation of FPN-1 and in the decreased export of cellular iron (Nemeth et al., 2004), which will be discussed below.

Both transcriptional and post-transcriptional mechanisms have been implicated in the regulation of FPN-1. They are induced by changes in the cellular iron status. Recently, in the duodena of iron-deficient mice, an $F P N-1$ transcript - ferroportin-1B (FPN-1B) which lacks IRE, so it is not regulated by the IRE/IRP system, has been identified (Zhang et al., 2009). Alternative transcripts of $F P N-1$ have been previously observed in human erythroid cells (Cianetti et al., 2005; Cianetti et al., 2010). On the basis of these findings, researchers (Zhang et al., 2009) proposed an updated model of duo- denal iron uptake, which expands the hepcidin-FPN-1 interaction model. During iron-replete conditions, both FPN-1 transcripts, i.e. $F P N-1 A$ and $F P N-1 B$ are translated into FPN-1 protein, which traffics to the basolateral membrane of the intestine to transport iron into the bloodstream. Once the iron stores are high, the liver produces hepcidin, which causes FPN-1 degradation and blocks iron absorption (Nemeth et al., 2004). During iron-deficient conditions, hepcidin expression decreases and the systemic iron-uptake blockage created by degradation of FPN-1 is eliminated. Iron deficiency state activates the IRE/IRP system, which then represses the translation of $F P N-1 A$. In iron deficiency anemia, the expression of $F P N-1 B$ increases markedly (as does $F P N-1 A$ ) and its ability to be translated into protein, regardless of IRP repressor activity, likely enables it to generate enough FPN-1 to satisfy the systemic iron demands (Zhang et al., 2009).

\section{Hepcidin - induces loss of ferroportin which decreases iron transfer to plasma}

In recent years, there has been important advancement in our understanding of iron metabolism, mainly as a result of the discovery of hepcidin (Park et al., 2001; Pigeon et al., 2001; Krause et al., 2000). This protein is encoded in humans by the hepcidin antimicrobial peptide $(H A M P)$ gene, initially identified as liver-derived antimicrobial peptide (LEAP). Its name originates from the place of the synthesis in hepatocytes (hep-) and its antimicrobial activity (-cidin) (Politou M. and Papanikolaou, 2004). Hepcidin is primarily expressed in the liver as a precursor pro-peptide. Pro-hepcidin undergoes proteolytic processing to yield a bioactive molecule of 25 amino acids that is secreted into the bloodstream (Wang and Pantopoulos, 2011). The mature hormone circulates in plasma and binds to $\alpha_{2}$-macroglobulin (Peslova et al., 2009). While this interaction was shown to promote hepcidin activity in vitro, the effect on hepcidin clearance is still unknown. A major route of hepcidin clearance is renal excretion. However, it may also be cleared by RME in tissues expressing its receptor FPN-1, as indicated by the accumulation of radiolabeled hepcidin in FPN-1-rich tissues (Nemeth and Ganz, 2009).

The main mechanism of hepcidin function seems to be the regulation of transmembrane iron transport. Hepcidin modulates cellular iron efflux by binding to FPN-1 at the cell surface and finally inducing FPN-1 degrada- 
tion (Nemeth et al., 2004; Singh et al., 2011; Franchini et al., 2010; Hentze et al., 2010).

In the recent past, major advances have been made in understanding the molecular mechanism of hepcidin regulation. The expression of hepcidin is controlled transcriptionally. Basal hepcidin transcription requires CCAAT/enhancer-binding protein- $\alpha(\mathrm{C} / \mathrm{EBP} \alpha)$ that belongs to a family of transcription factors that are critical for cellular differentiation and terminal function and inflammatory response (Courselaud et al., 2002). Hepcidin synthesis is modulated in response to several conditions, such as inflammatory process, iron stores (Pigeon et al., 2001), hypoxia and anemia (Nicolas et al., 2002). During inflammation, the availability of iron from stored forms and iron absorption tends to decrease leading to an increase in the amount of stored iron, which induces hepcidin synthesis. The disruption of hepcidin is associated with a systemic iron overload (hemochromatosis) (Lee and Beutler, 2009), whereas pathological elevation of hepcidin levels contributes to the development of an anemia of chronic disease (ACD) (Weiss and Goodnough, 2005) and a hereditary iron-refractory iron deficiency anemia (IRIDA) (Finberg, 2009; Weinstein et al., 2002).

Like other hormones, hepcidin is feedback-regulated by the substances whose concentration it controls, i.e. iron. This requires substances that function as intracellular and extracellular iron sensors coupled to transduction pathways that regulate its synthesis or secretion by the liver (Ganz and Nemeth, 2011). Studies related to primary hepatocytes show that hepcidin responds to serum iron level only when the iron is bound to $\mathrm{Tf}$ ( Lin et al., 2007). In vivo, the hepcidin response to dietary iron is proportional to the increase in the amount of iron carried by plasma $\mathrm{Tf}$ (i.e., transferrin saturation (TSAT)). The possible mechanism of this process is a cross-talk between the bone morphogenetic protein (BMP) and the mitogen-activated protein kinase (MAPK) signaling (Ramey et al., 2009). The BMP pathway, involved in cell proliferation, differentiation, and apoptosis, seems to be specifically regulated through a combination of two main factors: bone hemojuvelin (HJV) and morphogenetic protein-6 (BMP-6). HJV exists bound to the cell surface (a BMP membrane-anchored coreceptor) or in a circulating soluble form (sHJV) processed by furin. sHJV downregulates hepcidin in a competitive way interfering with BMP signaling (Silvestri et al., 2008). Thus, cell-surface HJV binds to BMP and stimulates BMP signaling and hepcidin synthesis, whereas the soluble form antagonizes this effect. Any stimulus that leads to increased synthesis of sHJV, lead to a reduction of hepcidin expression as well. It was found that iron treatment and hypoxia increases the generation of sHJV (Silvestri et al., 2008). As mentioned above, in addition to HJV, the second important factor that regulates human iron homeostasis is BMP. Iron triggers the expression of an ironspecific ligand - BMP6 in the liver and in the intestine, which is thought to be secreted into the plasma for binding to a BMP receptor (BMPR) on the hepatocytes surface. BMP6 signaling leads to the utilization of cytoplasmic proteins, called SMADs by phosphorylation of SMAD1/5/8 (Kautz L. et al., 2008) and translocation of SMAD family member 4 (SMAD4) to the nucleus (Wang et al., 2005; Meynard et al., 2009). In the nucleus, it promotes hepcidin transcription upon binding to proximal and distal sites on its promoter (Wang and Pantopoulos, 2011). Other BMPs, including BMP2, 4, 5, 7, 9 also have the ability to induce hepcidin expression, in vitro (Xia et al., 2008; Truksa et al., 2006), but their role in vivo still requires explanation. The last clinical findings suggest that the liver uses TSAT as an iron sensor. At the cellular level, iron sensing appears to involve transferrin receptor-2 (TfR2) because liver-specific disruption of TfR2 in mice markedly diminished hepcidin expression despite hepatic iron overload and substantially elevated TSAT (Collins et al., 2008). Moreover, the hemochromatosis protein (HFE) appears to be required for iron sensing because it was disclosed that patients with $\mathrm{HFE}$ mutations do not produce hepcidin in response to oral iron as normal individuals do (Piperno et al., 2007). In vivo studies suggest that HFE induces hepcidin expression only when it is not in complex with TfR1 (Collins et al., 2008; Schmidt et al., 2008). However, in vitro studies that show an interaction between HFE and TfR2 suggest that these molecules cooperate together to sense iron. It has been therefore proposed that HFE uncouples from TfR1 to form the HFE/TfR2/differicTf complex that enables up-regulation of hepcidin expression. This in turn, leads to a decrease in dietary iron uptake and reduction in iron recycling from macrophages in response to TSAT (Collins et al., 2008; Schmidt et al., 2008; Gao et al., 2009). It is possible that this complex potentiates BMP and/or MAPK pathway signaling. Whether HFE and TfR2 directly interact with BMP receptors and $\mathrm{HJV}$, or initiate a separate signaling cascade needs to be 
elucidated. Furthermore, in the response to Tf, hepatocytes can also increase the synthesis of hepcidin in response to stored intracellular iron. The mechanism of this process is still unclear, but some studies suggest that BMP6 concentration could reflect the intracellular iron levels in the hepatocyte.

Although hepcidin expression is expected to be low in iron deficiency, some clinical situations are more complex. Only recently, studies involving patients with ironrefractory anemia (IRA), have indicated a possibility of coexistence of high levels of hepcidin expression and iron deficiency. This helped to discover the role of transmembrane protease, serine 6 (TMPRSS6) in the regulation of hepcidin during iron deficiency. TMPRSS6 is expressed in the liver. Recent studies suggest that TMPRSS6 normally acts to down-regulate hepcidin expression by cleaving HJV (Silvestri et al., 2008).

As mentioned above, the inflammatory process has the ability to stimulate hepcidin. The inflammatory regulation of hepcidin gene expression involves transcriptional control through a signal transducer and activator of the transcription (STAT) site located on the hepcidin promoter. It was found that the pro-inflammatory cytokine interleukin-6 (IL-6) can influence hepcidin expression through the janus kinase - signal transducer and activator of transcription (JAK-STAT) signaling pathway, but this stimulation is dependent on an intact BMP-SMAD pathway as well (Darshan and Anderson, 2009). So, stimulation of IL-6 synthesis induces hepcidin transcription via a signal transducer, an activator of transcription-3 (STAT3) phosphorylation and translocation to the nucleus for binding to a proximal promoter element (Wang and Pantopoulos, 2011). Interestingly, IL-6 induction of hepcidin gene expression appears to be inactive when the signaling of hepatic SMAD4 is impaired (Wang et al., 2005), and lipopolysaccharide (LPS)-induced hepcidin up-regulation is attenuated by deficiency in BMP6 (Meynard et al., 2009). This indicates that SMAD signaling plays a key role in staging the appropriate response to inflammation (Wessling-Resnick, 2010). Furthermore, another cytokine, i.e. interleukin-1 $\beta$ (IL-1 $\beta$ ) activates hepcidin via the C/EBP $\alpha$ and BMP/SMAD pathways (Matak et al., 2009). It should also be mentioned that endoplasmic reticulum stress turns on hepcidin transcription via cyclic AMP response element-binding protein $\mathrm{H}(\mathrm{CREBH})$ and/or $\mathrm{C} / \mathrm{EBP}$ homologous protein
(CHOP) (Vecchi et al., 2009; Oliveira et al., 2009). LPS promotes hepcidin activation in macrophages via toll-like receptor 4 (TLR4) signaling (Peyssonnaux et al., 2006), whereas the pathogen Borrelia burgdorferi activates myeloid hepcidin via toll-like receptor 2 (TLR2) (Koening et al., 2009). Moreover, EPO signaling through erythropoietin receptor (EPOR) down-regulates hepcidin following the decreased binding of $\mathrm{C} / \mathrm{EBP} \alpha$ to its promoter (Pinto et al., 2008). Hepcidin transcription is also suppressed by hypoxia and oxidative stress. The hypoxia-inducible factors (HIF) pathway was shown to regulate hepcidin expression, in vivo (Volke et al., 2009; Nemeth, 2008). However, the role of HIFs in the hypoxic pathway of hepcidin is still not fully understood.

A scheme of the hepcidin regulation when diferric Tf concentration is high has been presented in Figure 2.

\section{Transportation of iron ions by transferrin}

Tf is the main serum iron transporter in all vertebrates. It takes up iron from duodenal enterocytes where iron is absorbed, and from macrophages when iron is recycled from senescent red blood cells, and delivers it to cells by binding TfR1. Physiologically, in a reaction with Concanavalin A, Tf occurs in four distinct variants: Tf1, Tf2, Tf3 and Tf4. Although we have little information about the participation of individual variations in the transport of iron, changes in their proportions seem to be important in maintaining the iron disturbances in chronic kidney disease (CKD) (Formanowicz and Formanowicz, 2011a). The Tf occupancy reflects the balance of iron entering the serum (from intestinal absorption, macrophage iron release, and hepatic iron mobilization) and iron leaving the serum (primarily for utilization in erythropoiesis). Iron uptake starts when Tf-Fe ${ }^{3+}$ binds TfR1. Under normal circumstances, all of non-heme iron in the circulation is bound to holotransferrin (HoloTf). Only about $30 \%$ of Tf-binding sites are occupied, so that most of the protein, which is called apotransferrin (ApoTf), is free of iron and is able to bind one or two $\mathrm{Fe}^{3+}$ ions at transferrins $\mathrm{N}$ - and/or C-terminal ends: $\left(\mathrm{Nt}\left(\mathrm{Fe}^{3+}\right)\right.$ HoloTf or HoloTf $\left(\mathrm{Fe}^{3+}\right) \mathrm{Ct}$ or HoloTf $\left(\mathrm{Fe}^{3+}\right)_{2}$ ) (Formanowicz et al., 2007). Monoferric Tf is the predominant form of Tf in circulation when transferrin saturation is lowered (Cazzola et al., 1987). However, each molecule of monoferric transferrin delivers less iron to erythroid precursors than diferric transferrin does (Huebers et al., 1984). 


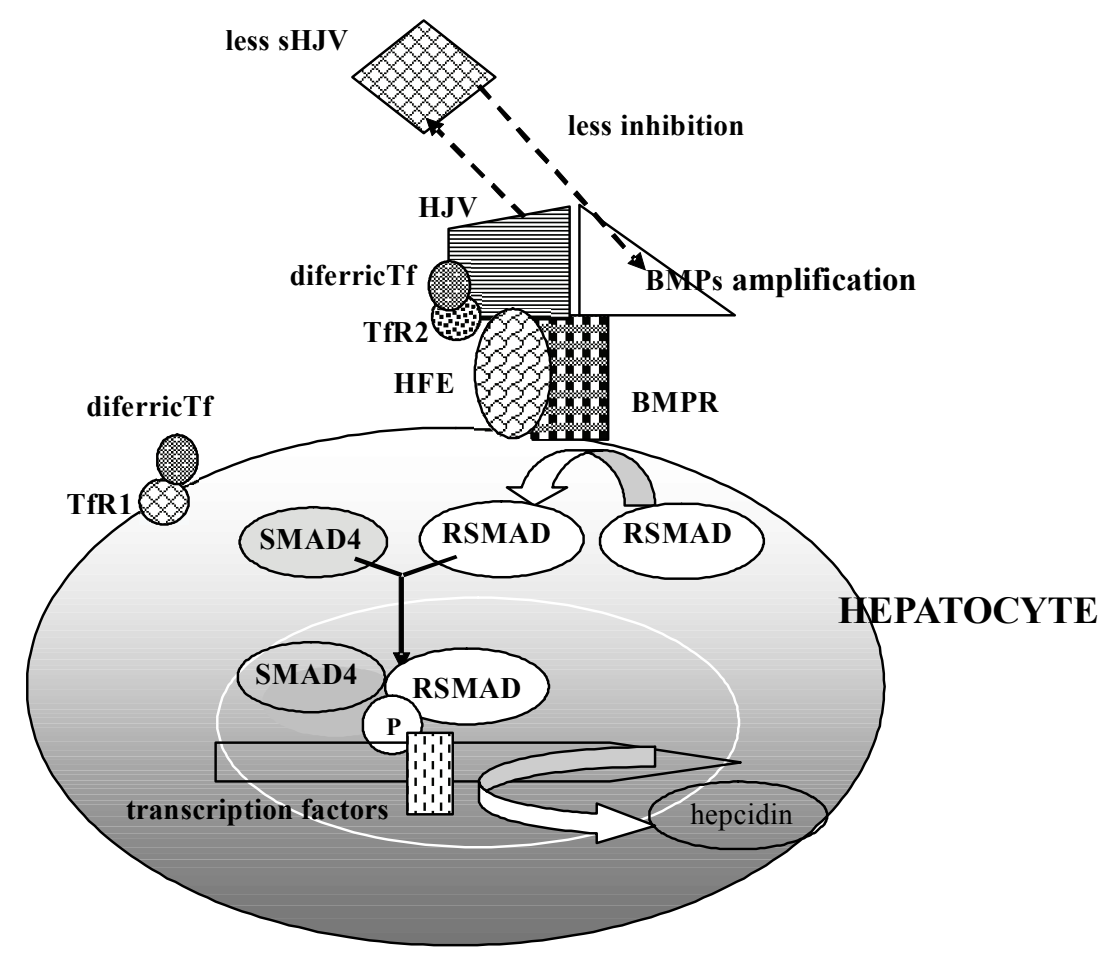

Fig. 2. Hepatic hepcidin regulation when differric Tf concentration is high (based on Nemeth E., 2008)

Differric Tf binds to transferrin receptors 1 and 2 (TfR1 and TfR2 respectively). As a result, TfR2 is stabilized and human hemochromatosis protein (HFE) dissociates from TfR1 and binds to TfR2. The HFE/TfR2 complex interacts with hemojuvelin (HJV), and less soluble HJV (sHJV) having ability to inhibit bone morphogenic protein signaling (BMP) pathway is generated. Thus, the BMP signaling pathway is intensified. Finally, it leads to the utilization of cytoplasmic proteins, called SMADs by their phosphorylation and translocation of SMAD family member 4 (SMAD4) to the nucleus, which results in increased hepcidin transcription.

TfR1 has much higher affinity for Fe-Tf than for ApoTf, which suggests that the competition between HFE and Tf for TfR1 binding might be modulated by Tf occupancy with iron. Furthermore, the fact that TfR2 expression is induced by Fe-Tf suggests that the HFE/ TfR2 interaction may also be altered by TSAT. It was hypothesized that the purposes of the HFE/TfR 1 and HFE/TfR2 interactions might therefore be the regulation of the hepcidin expression in response to body iron status (Schmidt et al., 2008).

On the cell surface, iron-bound HoloTf binds to TfR1 and as the HoloTf $\left(\mathrm{Fe}^{3+}\right)$-TfR1 complex is internalized, into endosomes by RME process through clathrin coated pits (Chung et al., 2009). After internalization of this complex, iron $\mathrm{Fe}^{3+}$ is released from HoloTf under the endosomal acidic conditions, then occurs in the reduced form as $\mathrm{Fe}^{2+}$ and forms ApoTf. Next, ApoTf and TfR1 complex (ApoTf-TfR1) is exocytosed. After the return of the complex to the cell surface, the extracellular $\mathrm{pH}$ triggers the release of ApoTf, allowing another round of binding and RME to begin.

\section{Iron distribution}

Iron distribution into body periphery is a complex issue. And so, one may distinguish flux through the erythron, flux through peripheral compartments with storage function (liver, muscles, intestinal tract, kidney, heart, lungs) and flux through organs with slow iron turn-over (testicles, fat, brain) (Lopes et al., 2010). The prevailing view is that all forms of iron entering cells reach a cytosolic pool of metabolically active or labile iron. This viewpoint will be discussed in the next section.

Iron gains entry into erythroid precursors when Tf$\mathrm{Fe}^{3+}$ binds TfR1, but what controls this distribution of iron to erythroid precursors is not completely understood (Li and Ginzburg, 2010). The amount of iron delivered to each erythroid precursor depends on the amount of monoferric and diferric Tf found in circulation as well as the density of TfR 1 on the cell surface. Typically, each erythroid precursor has over a million TfR1s on its membrane because of its large iron requirement for hemoglobin synthesis, relative to all other cells in the body (Muckenthaler et al., 2008). 
The mechanism by which cells alter their TfR 1 expression involves iron regulatory proteins (IRPs) which have a high affinity for IREs present in the mRNA of target genes involved in iron homeostatis. If an IRE is at the $5^{\prime}$ UTR, mRNA is more likely to be degraded and translation is blocked, whereas if it is at the $3^{\prime}$ UTR, it is more likely to be stabilized and translation is more efficient as a result of IRP binding. Thus, in an iron-depleted state, when IRPs are able to bind mRNA, ferritin mRNA with a $5^{\prime}$ UTR IRE is more likely to be degraded while TfR 1 mRNA with a 3' UTR IRE proceeds to translation more readily (Yeh et al., 2009). As a consequence of IRE/IRP regulation, iron deficiency is associated with high TfR1 expression and low ferritin concentrations (Murray-Kolb et al., 2003).

Iron in erythroid precursors is then transported to mitochondria for heme synthesis. Heme not participating in hemoglobin synthesis results in a down-regulation of IRP2 which reduces TfR1 expression at the cell surface and thus the amount of iron entering cells ( $\mathrm{Li}$ and Ginzburg, 2010). Ferritin is the major protein used for intracellular storage of iron. It serves to store iron in a non-toxic form and transports it to various tissues. However, the cellular mechanism used to absorb ferritin iron is still unknown. Since ferritin iron can be absorbed from soybean ferritin (SBFn), even in the presence of iron-binding inhibitors such as phytate (Murray-Kolb et al., 2003; San Martin et al., 2008), it is possible that at least part of the ferritin iron is absorbed by a mechanism distinct from transport of lower molecular weight iron complexes. High-affinity mammalian ferritin-binding sites have been reported in reticulocytes, lipocytes, hepatocytes, placenta, brain and kidney, although the mechanism of ferritin endocytosis has not been elucidated. Previous studies have indicated that iron may be taken up from ferritin via a ferritin receptor (Liao et al., 2001) and recent kinetic data supports these findings. A specific ferritin receptor has been found in Caco-2 cells (Kalgaonkar and Lönnerdal, 2009). It was also discovered that uptake of iron from ferritin affects the expression of iron transporters in a manner different from iron presented as ferrous sulfate. This supports the hypothesis that an uptake mechanism for ferritin iron differs from that for ferrous iron. So, it is possible that iron is taken up from intact (or partially digested) ferritin via endocytosis or that iron is released from ferritin and taken up as ferrous iron by DMT-1. It is not yet known if iron in the mineral core is released after ferritin digestion or if this mineral core remains intact for some time and is taken up by some yet unknown mechanism. It is also possible that iron is taken up from ferritin via a combination of these pathways, which may explain its high bioavailability (Lönnerdal, 2009).

Ferritin serves as the depot site for iron storage during sequestration responses caused by inflammatory response. In addition to the control by IRP of the actions triggered by iron in the liver and in other tissues, inflammatory cytokines regulate IRE/IRPs ferritin translation through an "acute-phase box" in the $5^{\prime}$ region of its transcript (Torti and Torti, 2002). The mechanisms of transcriptional control serve to further up-regulate ferritin expression, and increased serum ferritin levels are well recognized as a part of the acute-phase response (Wessling-Resnick, 2010; Torti and Torti, 2002). Ferritin serves as a suppressor of the reactive oxygen species (ROS) generation by sequestration of intracellular excess freeiron. The oxidative stress-mediated regulation of ferritin and frataxin - a mitochondrial protein that appears to regulate iron homeostasis and oxidative stress in mitochondria is now thoroughly tested. The function of frataxin is not fully explained but it seems to be involved in the assembly of Fe-S clusters. It has been proposed that it either acts as an iron chaperone or as an iron storage protein (Adinolfi et al., 2009).

The majority of intracellularly stored iron is found in liver, skeletal muscle and reticuloendothelial cells. If the storage capacity of ferritin is exceeded, iron will deposit adjacent to the ferritin-iron complexes in the cell. Histologically, those amorphous iron deposits are referred to as hemosiderin. Hemosiderin is composed of ferritin, denatured ferritin, and other materials, but its molecular structure is poorly defined. The iron present in hemosiderin is not readily available to the cell and thus cannot supply iron to the cell when it is needed. Hemosiderin is most frequently found in macrophages and is most abundant after hemorrhagic events.

\section{Labile iron pool}

The labile iron pool (LIP) is a compartment from which most of the metal is either metabolically drawn into Fe-dependent enzymes, transported into mitochondria for heme synthesis or incorporated into ferritin for secure storage and/or detoxification. LIP is composed of forms of iron bound to a variety of medium and low af- 
finity binding ligands. It might vary in composition and quantities in different physiological settings. Operationally, LIP can be regarded as that component of cell iron that is accessible to a particular chelator or a class of chelators. Topologically, it is identified primarily with the cytosol and as such, it is regarded as the crossroad of cellular iron traffic (Chung et al., 2009). Biochemically, LIP has been defined as the 'regulatory' or 'regulated' pool of cell iron, since depending on the cells system, its level is apparently maintained within a constant range.

The labile nature of LIP was also revealed by its capacity to promote the formation of ROS, whether from the endogenous or exogenous redox-active sources. LIP and ROS levels were shown to follow similar "rise and fall" patterns as a result of changes in iron import vs. iron chelation or ferritin degradation vs. ferritin synthesis. Those patterns conform with the accepted role of LIP as a self-regulatory pool that is sensed by cytosolic IRPs and feedback regulated by IRP-dependent expression of iron import and storage machineries. However, LIP can also be modulated by biochemical mechanisms that override the IRP regulatory loops and, thereby, contribute to basic cellular functions (Kakhlona and $\mathrm{Ca}$ bantchik, 2002).

\section{The formal model of the process}

As can be seen from the previous sections, the regulation of iron metabolism is a very complex process. Probably, most of the components of this process are known but we cannot be sure that all of them have already been discovered. Hepcidin, which has been known for only a few years, may serve as an example supporting the hypothesis that it is possible that even very important components of iron homeostasis process may still wait for being discovered. Moreover, not only the components of the process but also the dense network of interactions among them is crucial for the proper regulation of iron metabolism. The latter is a special case of a more general rule which becomes more and more obvious. According to this rule most of the biological processes are, in fact, complex systems whose nature and functionality is a reflextion of the interactions taking place among their elements. Hence, a detailed analysis of such systems requires proper mathematical and computational tools. The basis of such an analysis is a precise model of the studied system. Such a model can be expressed as ordinary differential equations which are quite often used to model biological phenomena. However, models based on equations of this type usually require precise values of some parameters. Unfortunately, these values are often difficult to obtain in practice, which limits the application of the models. An interesting alternative for models based on differential equations are models based on a graph theory. The latter ones usually describe qualitative rather than quantitative properties of the analyzed system, so it is possible to abstract (at least to some extent) from exact values of parameters required by differential equations. In addition, graphs very well match the network structure of the interactions taking place among the elementary components of biological systems. What is more, graphs are very similar to the network structure. So, it should not be surprising that they are more and more often used in systems approach to the analysis of biological phenomena.

One of the special cases of graph theory based models are those which are expressed in the language of Petri nets theory. Such nets are composed of vertices of two types, called places and transitions, connected by arcs in such a way that if a starting vertex of an arc is a place then its ending vertex is a transition and vice versa. In a biological context, the transitions represent some reactions while the places correspond to components needed for a reaction to take place or produced as a result of its execution. As it is easy to guess, arcs represent causal relations between components and reactions (for more details see (Błażewicz et al., 2009a; Sackmann et al., 2007).

The Petri net theory has been recently used to formulate a precise model of the main part of the iron metabolism process (Formanowicz et al., 2007; Sackmann et al., 2007). The model describes detailed qualitative relationships between the elementary components of the process in a mathematically rigorous way, which at the same time, is relatively easy to understand even for those who are not familiar with the graph theory. Despite the fact that many processes involved in iron metabolism have been described in literature, this model is the first mathematical description of the human iron homeostasis (see (Curis et al., 2009) for a recent review of mathematical modeling of metal metabolism). One of the advantages of the Petri net based models is the availability of many software tools for simulation and analysis of formal properties of the models, which may 
lead to discoveries of some biological properties not yet known. The first model of iron metabolism has been extended by inclusion of available knowledge of hepcidin (Sackmann et al., 2009) and some time dependencies (Błażewicz et al., 2009b). It may be a basis for a detailed analysis of the regulation of iron metabolism which would be impossible without such a formal description of the process. The model is a starting point for an analysis characteristic for systems biology where an investigation of formal properties of the theoretical model of a biological system leads to discovering unknown aspects of the system. The analysis allows to observe complex relationships between different parts of the modeled system which are difficult to discover without an application of formal methods. Although that model is only the first step in this direction, some biological discoveries have already been made on this basis (Formanowicz et al., 2011b).

It is worth mentioning that the development of a mathematical model of a biological system and the discovery of some unknown features of the system on the basis of that model is, in general, an iterative and cyclic process. Indeed, when the model is formulated, an analysis of its formal properties may lead to discoveries of some new properties of the system. These properties may be then verified in laboratory experiments or through clinical data. The obtained results may lead to the creation of a more precise model. A more accurate model may subsequently make new discoveries possible. After all, the amount of available information on the analyzed system increases as a result of this iterative process.

\section{Conclusions}

In this work, the main part of the whole process of the regulation of iron metabolism has been presented. The paper highlights the importance of many proteins, among others, hepcidin, ferroportin, transferrin, involved in maintaining iron balance in the human body. Knowledge of iron metabolism has been considerably expanded in recent years. The application of new techniques has enabled the detection of novel interactions between various elements of this complex puzzle of iron homeostasis maintenance. Moreover, computational and systems biology approaches for studying biological phenomena have been recently applied to the analysis of iron homeostasis. This opens new possibilities towards complete understanding of the complex and crucial biochemical process that is being considered in this paper.

\section{Acknowledgements}

This work was partially supported by the Polish Ministry of Science and Higher Education grant no. NN 402209833.

\begin{tabular}{|c|c|}
\hline \multicolumn{2}{|r|}{ Abbreviations } \\
\hline $\mathrm{ABCB} 6$ & ATP-binding cassette, sub-family B, member 6 \\
\hline $\mathrm{ABCB} 7$ & ATP-binding cassette, sub-family B, member 7 \\
\hline $\mathrm{ABCB} 10$ & ATP-binding cassette, sub-family B, member 10 \\
\hline ABCG2 & ATP-binding cassette sub-family G member 2 \\
\hline $\mathrm{ABCP}$ & placenta-specific $\mathrm{ABC}$ transporter \\
\hline $\mathrm{ACD}$ & $\begin{array}{l}\text { anemia of chronic disease/anemia of chronic dis- } \\
\text { orders }\end{array}$ \\
\hline ApoTf & apotransferrin \\
\hline BCRP & breast cancer resistance protein \\
\hline BMP & bone morphogenetic protein \\
\hline BMP2 & bone morphogenetic protein- 2 \\
\hline BMP4 & bone morphogenetic protein- 4 \\
\hline BMP5 & bone morphogenetic protein- 5 \\
\hline BMP6 & bone morphogenetic protein- 6 \\
\hline BMP7 & bone morphogenetic protein- 7 \\
\hline BMP9 & bone morphogenetic protein- 9 \\
\hline BMPR & bone morphogenetic protein receptor \\
\hline $\mathrm{C} / \mathrm{EBP} \alpha$ & CCAAT/enhancer-binding protein- $\alpha$ \\
\hline $\mathrm{CHOP}$ & C/EBP homologous protein \\
\hline $\mathrm{Cp}$ & ceruloplasmin \\
\hline CREBH & cyclic-AMP response element-binding protein $\mathrm{H}$ \\
\hline CYBRD-1 & cytochrome b reductase- 1 \\
\hline DCT-1 & divalent cation transporter- 1 \\
\hline DCYTB & duodenal cytochrome b \\
\hline DMT-1 & divalent metal transporter- 1 \\
\hline EPO & erytrhopoietin \\
\hline EPOR & erythropoietin receptor \\
\hline FLVCR & feline leukemia virus, subgroup $\mathrm{C}$ receptor \\
\hline FPN-1 & ferroportin-1 \\
\hline FPN-1A & ferroportin-1A \\
\hline FPN-1B & ferroportin-1B \\
\hline HAMP & hepcidin antimicrobial peptide \\
\hline $\mathrm{Hb}$ & hemoglobin \\
\hline HCP-1 & heme carrier protein- 1 \\
\hline $\mathrm{HEPH}$ & hephaestin \\
\hline $\mathrm{HFE}$ & human hemochromatosis protein \\
\hline HIFs & hypoxia-inducible factors \\
\hline HJV & hemojuvelin \\
\hline $\mathrm{HO}$ & heme oxygenase \\
\hline $\mathrm{HO}-1$ & heme oxygenase-1 \\
\hline HO-2 & heme oxygenase- 2 \\
\hline HoloTf & holotransferrin \\
\hline $\mathrm{Hp}$ & haptoglobin \\
\hline HPX & hemopexin \\
\hline IL-1 $\beta$ & interleukin-1 $\beta$ \\
\hline IL-6 & interleukin-6 \\
\hline IRE & iron-responsive element \\
\hline
\end{tabular}




\begin{tabular}{|c|c|}
\hline IREG-1 & iron-regulated transporter-1 \\
\hline IRA & iron-refractory anemia \\
\hline IRIDA & iron-refractory iron deficiency anemia \\
\hline IRP & iron-regulated protein \\
\hline JAK-STAT & $\begin{array}{l}\text { janus kinase - signal transducer and activator } \\
\text { of transcription }\end{array}$ \\
\hline LEAP & liver-derived antimicrobial peptide \\
\hline LIP & labile iron pool \\
\hline LPS & lipopolysaccharide \\
\hline MAD & mothers against decapentaplegic \\
\hline MAPK & mitogen-activated protein kinase \\
\hline MTP-1 & metal transporter protein-1 \\
\hline MXR & mitoxantrone resistance protein \\
\hline Nramp-1 & $\begin{array}{l}\text { natural resistance-associated macrophage pro- } \\
\text { tein-1 }\end{array}$ \\
\hline Nramp2 & $\begin{array}{l}\text { natural resistance-associated macrophage pro- } \\
\text { tein-2 }\end{array}$ \\
\hline PCTF & proton-coupled folate transporter \\
\hline RME & receptor-mediated endocytosis \\
\hline ROS & reactive oxygen species \\
\hline SBFn & soybean ferritin \\
\hline SLC & $\begin{array}{l}\text { solute carrier group of membrane transport pro- } \\
\text { teins }\end{array}$ \\
\hline SLC40A1 & solute carrier family 40, member 1 \\
\hline SLC11A2 & solute carrier family 11 , member 2 \\
\hline SLC11A3 & solute carrier family 11 , member 3 \\
\hline sHJV & soluble hemojuvelin \\
\hline SMADs & $\begin{array}{l}\text { homologs of both the drosophila protein, mothers } \\
\text { against decapentaplegic (MAD) and the Caeno- } \\
\text { rhabditis elegans protein SMA. The name is } \\
\text { a combination of the two }\end{array}$ \\
\hline SMAD4 & SMAD family member 4 \\
\hline STAT3 & signal transducer and activator of transcription-3 \\
\hline $\mathrm{Tf}$ & transferrin \\
\hline TfR1 & transferrin receptor-1 \\
\hline TfR2 & transferrin receptor- 2 \\
\hline TGF- $\beta$ & transforming growth factor beta \\
\hline TNF- $\alpha$ & tumor necrosis factor alpha \\
\hline TLR2 & toll-like receptor 2 \\
\hline TLR4 & toll-like receptor 4 \\
\hline TMPRSS6 & transmembrane protease, serine 6 \\
\hline TSAT & transferrin saturation \\
\hline
\end{tabular}

\section{References}

Abboud S., Haile D.J. (2000) A novel mammalian iron-regulated protein involved in intracellular iron metabolism. J. Biol. Chem. 275: 19906-19912.

Adinolfi S., Iannuzzi C., Prischi F., Pastore C., Iametti S., Martin S.R., Bonomi F., Pastore A. (2009) Bacterial frataxin CyaY is the gatekeeper of iron-sulfur cluster formation catalyzed by IscS. Nat. Struct. Mol. Biol. 16: 390-396.

Anderson G.J., Darshan D., Wilkins S.J., Frazer D.M. (2007) Regulation of systemic iron homeostasis: how the body responds to changes in iron demand. Biometals 20: 665-674.
Błażewicz J., Formanowicz D., Formanowicz P. (2009a) Zastosowanie sieci Petriego do modelowania procesów biologicznych. Kosmos 58: 79-88.

Błażewicz J., Formanowicz D., Formanowicz P., Sackmann A., Sajkowski M. (2009b) Modeling the process of human body iron homeostasis using a variant of timed Petri nets. Discrete Appl. Math. 157: 2221-2231.

Canonne-Hergaux F., Gruenheid S., Ponka P., Gros P. (1999) Cellular and subcellular localization of the Nramp2 iron transporter in the intestinal brush border and regulation by dietary iron. Blood 93: 4406-4417.

Canonne-Hergaux F., Zhang A.S., Ponka P., Gros P. (2001) Characterization of the iron transporter DMT1 (NRAMP2 /DCT1) in red blood cells of normal and anemic $\mathrm{mk} / \mathrm{mk}$ mice. Blood 98: 3823-3830.

Cazzola M., Pootrakul P., Bergamaschi G., Huebers H.A., Eng M., Finch C.A. (1987) Adequacy of iron supply for erythropoiesis: in vivo observations in humans. J. Lab. Clin. Med. 110: 734-739.

Chung B., Rapisarda C., Pourvali K., Sharp P. (2009) Direct effects of erythropoietin on iron absorption by human in testinal epithelial cells. Newcastle Univ. Proc. Physiol. Soc. 16: C12 [abstract].

Cianetti L., Segnalini P., Calzolari A., Morsilli O., Felicetti F., Ramoni C., Gabbianelli M., Testa U., Sposi N.M. (2005) Expression of alternative transcripts of ferroportin-1 during human erythroid differentiation. Haematologica 90: 1595-1606.

Cianetti L., Gabbianelli M., Sposi N.M. (2010) Ferroportin and erythroid cells: An update. Adv. Hematol. Article ID 404173.

Collins J.F., Wessling-Resnick M., Knutson M.D. (2008) Hepcidin Regulation of Iron Transpor. J. Nutr. 138: 2284-2288.

Courselaud B., Pigeon C., Inoue Y., Inoue J., Gonzalez F.J., Leroyer P., Gilot D., Boudjema K., Guguen-Guillouzo C., Brissot P. (2002) C/EBP $\alpha$ regulates hepatic transcription of hepcidin, an antimicrobial peptide and regulator of iron metabolism. Cross-talk between C/EBP pathway and iron metabolism. J. Biol. Chem. 277: 41163-41170.

Curis E., Nicolis I., Bensaci J., Deschamps P., Bénazeth S. (2009) Mathematical modeling in iron metabolism: over view and perspectives. Biochimie 91: 1238-1254.

Darshan D., Anderson G.J. (2009) Interacting signals in the control of hepcidin expression. Biometals 22: 77-87.

Donovan A., Brownlie A., Zhou Y., Shepard J., Pratt S.J., Moynihan J., Paw B.H., Drejer A., Barut B., Zapata A., Law T.C., Brugnara C., Lux S.E., Pinkus G.S., Pinkus J.L., Kingsley P.D., Palis J., Fleming M.D., Andrews N.C, Zon L.I. (2000) Positional cloning of zebrafish Ferroportin 1 identifies a conserved vertebrate iron exporter. Nature 403: 778-781.

Donovan A., Lima C.A., Pinkus J.L., Pinkus G.S., Zon L.I., Robine S., Andrews N.C. (2005) The iron exporter ferroportin/Slc40a1 is essential for iron homeostasis. Cell Metab. 1: 191-200. 
Ferguson C.J., Wareing M., Ward D.T., Green R., Smith C.P., Riccardi D. (2001) Cellularlocalization of divalent metal transporter 1 in rat kidney. Am. J. Physiol. Renal Physiol. 280: F803-F814.

Finberg K.E. (2009) Iron-refractory iron deficiency anemia. Semin. Hematol. 46: 378-386.

Formanowicz D., Sackmann A., Formanowicz P., Błażewicz J. (2007) Petri net based model of the body iron homeostasis. J. Biomed. Inform. 40: 476-485.

Formanowicz D., Formanowicz P. (2011a) Transferrin changes in haemodialysed patients. Int. Urol. Nephrol. DOI 10.1007/s11255-011-9947-4.

Formanowicz D., Sackmann A., Formanowicz P., Kozak A., Błażewicz J. (2011b) Some aspects of the anemia of chronic disease modeled and analyzed by petri net based approach. Bioprocess. Biosyst. Eng. 34: 581-595.

Franchini M., Montagnana M., Lippi G. (2010) Hepcidin and iron metabolism: From labolatory to clinical implications. Clin. Chim. Acta 411: 1565-1569.

Ganz T., Nemeth E. (2011) Hepcidin and disorders of iron metabolism. Annu. Rev. Med. 62: 347-360.

Gao J., Chen J., Kramer M., Tsukamoto H., Zhang A.S., Enns C.A. (2009) Interaction of the hereditary hemochromatosis protein HFE with transferrin receptor 2 is required for transferrin-induced hepcidin expression. Cell Metab. 9: 217-227.

Georgieff M.K., Wobken J.K., Welle J., Burdo J.R., Connor J.R. (2000) Identification and localization of divalent metal transporter-1 (DMT-1) in term human placenta. Placenta 21: 799-804.

Gunshin H., Mackenzie B., Berger U.V., Gunshin Y., Romero M.F., Boron W.F., Nussberger S., Gollan J.L., Hediger M.A. (1997) Cloning and characterization of a mammalian proton-coupled metal-ion transporter. Nature 388: 482 488.

Gunshin H., Fujiwara Y., Custodio A., DiRenzo C., Robine S., Andrews N.C. (2005) Slc11a2 is required for intestinal iron absorption and erythropoiesis but dispensable in placenta and liver. J. Clin. Invest. 115: 1258-1266.

Hentze M.W., Muckenthaler M.U., Galy B., Camaschella C. (2010) Two to tango: regulation of mammalian iron metabolism. Cell 142: 24-38.

Huebers H.A., Finch C.A. (1987) The physiology of transferrin and transferrin receptors. Physiol. Rev. 67: 520-582.

Huebers H.A., Josephson B., Huebers E., Csiba E., Finch C.A. (1984) Occupancy of the iron binding sites of human transferrin. Proc. Natl. Acad. Sci. USA 81: 4326-4330.

Inoue K., Nakai Y., Ueda S., Kamigaso S., Ohta K, Hatakeyama M., Hayashi Y., Otagiri M., Yuasa H. (2008) Functional characterization of PCFT/HCP1 as the molecular entity of the carrier-mediated intestinal folate transport system in the rat model. Am. J. Physiol. Gastrointest. Liver. Physiol. 294: 660-668.

Kakhlona O., Cabantchik Z.I. (2002) The labile iron pool: characterization, measurement, and participation in cellular processes. Free Radic. Biol. Med. 33: 1037-1046.
Kalgaonkar S., Lönnerdal B. (2009) Receptor-mediated uptake of ferritin-bound iron by human intestinal Caco-2 cells. J. Nutr. Biochem. 20: 304-311.

Kautz L., Meynard D., Monnier A., Darnaud V., Bouvet R., Wang R.H., Deng C., Vaulont S., Mosser J., Coppin H., Roth M.P. (2008) Iron regulates phosphorylation of Smad1 15/8 and gene expression of Bmp6, Smad7, Id1, and Atoh8 in the mouse liver. Blood 112: 1503-1509.

Keel S.B., Doty R.T., Yang Z., Quigley J.G., Chen J., Knoblaugh S., Kingsley P.D., De Domenico I., Vaughn M.B., Kaplan J., Palis J., Abkowitz J.L. (2008) Heme export protein is required for red blood cell differentiation and iron homeostasis. Science 319: 825-828A.

Khan A.A., Quigley J.G. (2011) Control of intracellular heme levels: Heme transporters and heme oxygenases. Biochim. Biophys. Acta 1813: 668-682.

Knutson M.D, Vafa M.R., Haile D.J., Wessling-Resnick M. (2003) Iron loading and erythrophagocytosis increase ferroportin 1 (FPN1) expression in J774 macrophages. Blood 102: 4191-4197.

Knutson M.D., Oukka M., Koss L.M., Aydemir F., WesslingResnick M. (2005) Iron release from macrophages after erythrophagocytosis is up-regulated by ferroportin 1 overexpression and down-regulated by hepcidin. Blood 102: 1324-1328.

Koening C.L., Miller J.C., Nelson J.M., Ward D.M., Kushner J.P., Bockenstedt L.K., Weis J.J., Kaplan J., De Domenico I. (2009) Toll-like receptors mediate induction of hepcidin in mice infected with Borrelia burgdorferi. Blood 114: 1913-1918.

Krause A., Neitz S., Mägert H.-J., Schulz A., Forssmann W.G., Schulz-Knappe P., Adermann K. (2000) LEAP-1, a novel highly disulfide-bonded human peptide, exhibits antimicrobial activity. FEBS Lett. 480: 147-150.

Latunda-Dada G.O., Takeuchi R., Simpson R.J., McKie A.T. (2006) Haem carrier protein 1 (HCP1): Expression and functional studies in cultured cells. FEBS Lett. 580: 6865-6870.

Lee P.L., Beutler E. (2009) Regulation of hepcidin and ironoverload disease. Annu. Rev. Pathol. 4: 489-515.

Li H., Ginzburg Y.Z. (2010) Crosstalk between iron metabolism and erythropoiesis. Adv. Hematol. doi: 10.1155/2010/ 605435.

Liao Q.K., Kong P.A., Gao J., Li F.Y., Qian Z.M. (2001) $E_{X^{-}}$ pression of ferritin receptor in placental microvilli membrane in pregnant women with different iron status at midterm gestation. Eur. J. Clin. Nutr. 55: 651-656.

Lin L., Valore E.V., Nemeth E., Goodnough J.B., Gabayan V., Ganz T. (2007) Iron-transferrin regulates hepcidin synthesis in primary hepatocyte culture through hemojuvelin and BMP2/4. Blood 110: 2182-2189.

Lopes T.J.S., Luganskaja T., Vujić Spasić M., Hentze M.W., Muckenthaler M.U., Schümann K., Reich J.G. (2010) Systems analysis of iron metabolism: the network of iron pools and fluxes. BMC Syst. Biol. 4: 112.

Lönnerdal B. (2009) Soybean ferritin: implications for iron status of vegetarians. Am. J. Clin. Nutr. 89: 1S-6S. 
Lymboussaki A., Pignatti E., Montosi G., Garuti C., Haile D.J., Pietrangelo A. (2003) The role of the iron responsive element in the control of ferroportin1/IREG1/MTP1 gene expression. J. Hepatol. 39: 710-715.

Matak P., Chaston T.B., Chung B., Srai S.K., McKie A.T., Sharp P.A. (2009) Activated macrophages induce hepcidin expression in HuH7 hepatoma cells. Haematologica 94: 773-780.

McKie A.T, Marciani P., Rolfs A., Brennan K., Wehr K., Barrow D., Miret S., Bomford A., Peters T.J., Farzaneh F., Hediger M.A., Hentze M.W., Simpson R.J. (2000) A novel duodenal iron-regulated transporter, IREG1, implicated in the basolateral transfer of iron to the circulation. Mol. Cell. 5: 299-309.

McKie A.T., Barlow D.J. (2004) The SLC40 basolateral iron transporter family (IREG1/ferroportin/MTP1). Eur. J. Physiol. 447: 801-806.

Meynard D., Kautz L., Darnaud V., Canonne-Hergaux F., Coppin H., Roth M.P. (2009) Lack of the bone morphogenetic protein BMP6 induces massive iron overload. Nat. Genet. 41: 478-481.

Muckenthaler M.U., Galy B., Hentze M.W. (2008) Systemic iron homeostasis and the iron-responsive element/ironregulatory protein (IRE/IRP) regulatory network. Ann. Rev. Nutr. 28: 197-213.

Murray-Kolb L.E., Welch R., Theil E.C., Beard J.L. (2003) Women with low iron stores absorb iron from soybeans. Am. J. Clin. Nutr. 77: 180-184.

Nemeth E., Tuttle M.S., Tuttle M.S. (2004) Hepcidin regulates cellular iron efflux by binding to ferroportin and inducing its internalization. Science 306: 2090-2093.

Nemeth E. (2008) Iron regulation and erythropoesis. Curr. Opin. Hematol. 15: 169-175.

Nemeth E., Ganz T. (2009) The role of hepcidin in iron meta bolism. Acta Haematol. 122: 78-86.

Nicolas G., Chauvet C., Viatte L., Danan J.L., Bigard X., Devaux I., Beaumont E., Kahn A., Vaulont S. (2002) The gene encoding the iron regulatory peptide hepcidin is regulated by anemia, hypoxia, and inflammation. J. Clin. Invest. 110: 1037-1044.

Oliveira S.J., Pinto J.P., Picarote G., Costa V.M., Carvalho F., Rangel M., de Sousa M., de Almeida S.F. (2009) ER stressinducible factor $C H O P$ affects the expression of hepcidin by modulating $C / E B P \alpha$ activity. PLoS ONE 4: e6618.

Quigley J.G., Yang Z., Worthington M.T., Phillips J.D., Sabo K.M., Sabath D.E., Berg, C.L., Sassa S., Wood B.L., Abkowitz J.L. (2004) Identification of human heme exporter that is essential for erythropoesis. Cell 118: 757-766.

Park C.H., Valore E.V., Waring A.J., Ganz T. (2001) Hepcidin, a urinary antimicrobial peptide synthesized in the liver. J. Biol. Chem. 276: 7806-7810.

Peslova G., Petrak J., Kuzelova K., Hrdy I., Halada P., Kuchel P.W., Soe-Lin S., Ponka P., Sutak R., Becker E., Huang M.L., Suryo R.Y, Richardson D.R, Vyoral D. (2009) Hepcidin, the hormone of iron metabolism, is bound specifically to alpha-2-macroglobulin in blood. Blood 113: 6225-6236.
Peyssonnaux C., Zinkernagel A.S., Datta V., Lauth X., Johnson R.S., Nizet V. (2006) TLR4-dependent hepcidin expression by myeloid cells in response to bacterial pathogens. Blood 107: 3727-3732.

Pigeon C., Ilyin G., Courselaud B., Leroyer P., Turlin B., Brissot P., Loreal O. (2001) A new mouse liver-specific gene, encoding a protein homologous to human antimicrobial peptide hepcidin, is overexpressed during iron overload. J. Biol. Chem. 276: 7811-7819.

Pinto J.P., Ribeiro S., Pontes H., Thowfeequ S., Tosh D., Carvalho F., Porto G. (2008) Erythropoietin mediates hepcidin expression in hepatocytes through EPOR signaling and regulation of $C / E B P \alpha$. Blood 111: 5727-5733.

Piperno A., Girelli D., Nemeth E. Bozzini C., Poggiali E., Phung Y., Ganz T., Camaschella C. (2007) Blunted hepcidin response to oral iron challenge in HFE-related hemochromatosis. Blood 110: 4096-4100.

Politou M., Papanikolaou G. (2004) Hepcidin: A key iron regulator involved in the pathogenesis of anaemia of chronic disease. Haema 7: 165-174.

Ramey G., Deschemin J.C., Vaulont S. (2009) Cross-talk between the mitogen activated protein kinase and bone morphogenetic protein/hemojuvelin pathways is required for the induction of hepcidin by holotransferrin in primary mouse hepatocytes. Haematologica 94: 765-772.

Sackmann A., Formanowicz D., Formanowicz P., Koch I., Błażewicz J. (2007) An Analysis of the Petri Net based model of the Human Body Homeostasis Process. Comput. Biol. Chem. 31: 1-10.

Sackmann A., Formanowicz D., Formanowicz P., Błażewicz J. (2009) New insights into the human body iron metabolism analysed by a Petri net based approach. Biosystems 96: 104-113.

San Martin C.D., Garri C., Pizarro F., Walter T., Theil E.C., Núñez M.T. (2008) Caco-2 intestinal epithelial cells absorb soybean ferritin by $\mu_{2}$ (AP2)-dependent endocytosis. J. Nutr. 138: 659-666.

Schaer C.A., Vallelian F., Imhof A., Schoedon G., Schaer D.J. (2008) Heme carrier protein (HCP-1) spatially interacts with the CD163 hemoglobin uptake pathway and is a target of inflammatory macrophage activation. J. Leukoc. Biol. 83: 325-333.

Schmidt P.J., Toran P.T., Giannetti A.M., Bjorkman P.J., Andrews N.C. (2008) Transferrin receptor modulates Hfe-dependent regulation of hepcidin expression. Cell Metab. 7: 205-214.

Sharp P., Tandy S., Yamaji S., Tennant J., Williams M., Singh Srai S.K. (2002) Rapid regulation of divalent metal transporter (DMT1) protein but not $m R N A$ expression by nonhaem iron in human intestinal Caco-2 cells. FEBS Lett. 510: 71-76.

Shayeghi M., Gladys O., Latunde-Dada Oakhill J.S, Laftah A.H., Takeuchi K., Halliday N., Khan Y., Warley A., McCann F.E, Hider R.C, Frazer D.M, Anderson G.J., Vulpe C.D., Simpson R.J., McKie A.T. (2005) Identification of an intestinal heme transporter. Cell 122: 789-801. 
Shirase T., Mori K., Okazaki Y., Itoh K., Yamamoto M., Tabuchi M., Kishi F., Jiang L., Akatsuka S., Nakao K., Toyokuni S. (2010) Suppression of SLC11A2 expression is essential to maintain duodenal integrity during dietary iron overload. Am. J. Pathol. 177: 677-685.

Silvestri L., Pagani A., Camaschella C. (2008) Furin-mediated release of soluble hemojuvelin: a new link between hypoxia and iron homeostasis. Blood 111: 924-931.

Silvestri L., Pagani A., Nai A., De Domenico I., Kaplan J., Camaschella C. (2008) The serine protease matriptase-2 (TMPRSS6) inhibits hepcidin activation by cleaving membrane hemojuvelin. Cell Metab. 8: 502-511.

Singh B., Arora S., Agrawal P., Gupta S.K. (2011) Hepcidin. $A$ novel peptide hormone regulating iron metabolism. Clin. Chim. Acta 412: 823-830.

Soe-Lin S., Apte S.S., Andriopoulos B., Andrews M.C., Schranzhofer M., Kahawita T., Garcia-Santos D., Ponka P. (2009) Nramp1 promotes efficient macrophage recycling of iron following erythrophagocytosis in vivo. Proc. Natl. Acad. Sci. USA 106: 5960-5965.

Theurl I., Ludwiczek S., Eller P., Seifert M., Artner E., Brunner P., Weiss G. (2005) Pathways for the regulation of body iron homeostasis in response to experimental iron overload. J. Hepatol. 43: 711-719.

Torti F.M., Torti S.V. (2002) Regulation of ferritin genes and protein. Blood 99: 3505-3516.

Trinder D., Oates P.S., Thomas C., Sadleir J., Morgan E.H. (2000) Localisation of divalent metal transporter 1 (DMT1) to the microvillus membrane of rat duodenal enterocytes in iron deficiency, but to hepatocytes in iron overload. Gut 46: 270-276.

Truksa J., Peng H., Lee P., Beutler E. (2006) Bone morphogenetic proteins 2, 4, and 9 stimulate murine hepcidin 1 expression independently of Hfe, transferrin receptor 2(Tfr2), and IL-6. Proc. Natl. Acad. Sci. USA 103: 10289-10293.

Vecchi C., Montosi G., Zhang K., Lamberti I., Duncan S.A., Kaufman R.J., Pietrangelo A. (2009) ER stress controls iron metabolism through induction of hepcidin. Science 325: 877-880.

Veuthey T., D'Anna M.C, Roque M.A. (2008) Role of the kidney in iron homeostasis: renal expression of prohepcidin, ferroportin, and DMT1 in anemic mice. Am. J. Physiol. Renal. Physiol. 295: F1213-F1221.

Volke M., Gale D.P., Maegdefrau U., Schley G., Klanke B., Bosserhoff A.K., Maxwell P.H., Eckardt K.U., Warnecke C. (2009) Evidence for a lack of a direct transcriptional suppression of the iron regulatory peptide hepcidin by hypoxia-inducible factors. PLoS ONE 4: e7875.

Vulpe C.D., Kuo Y.M., Murphy T.L., Cowley L., Askwith C., Libina N., Gitschier J., Anderson G.J. (1999) Hephaestin, a ceruloplasmin homologue implicated in intestinal iron transport, is defective in the sla mouse. Nat. Genet. 21: 195-199.

Wang J., Pantopoulos K. (2011) Regulation of cellular iron metabolism. Biochem. J. 434: 365-381.

Wang R.H., Li C., Xu X., Zheng Y., Xiao C., Zerfas P., Cooperman S., Eckhaus M., Rouault T., Mishra L., Deng C.X. (2005) A role of SMAD4 in iron metabolism through the positive regulation of hepcidin expression. Cell Metab. 2: 399-409.

Weinstein D.A., Roy C.N., Fleming M.D., Loda M.F., Wolfsdorf J.I., Andrews N.C. (2002) Inappropriate expression of hepcidin is associated with iron refractory anemia: implications for the anemia of chronic disease. Blood 100: 3776-3781.

Weiss G., Goodnough L.T. (2005) Anemia of chronic disease. N. Engl. J. Med. 352: 1011-1023.

Wessling-Resnick M. (2010) Iron homeostasis and the inflammatory response. Annu. Rev. Nutr. 30: 105-122.

West A.R., Oates P.S. (2008) Mechanisms of heme iron absorption: Current questions and controversies. World J. Gastroenterol. 14: 4101-4110.

Wolff N.A., Liu W., Fenton R.A., Lee W.-K., Thévenod F., Smith C.P. (2011) Ferroportin 1 is expressed basolaterally in rat kidney proximal tubule cells and iron excess increases its membrane trafficking. J. Cell Mol. Med. 15: 209-219.

Wyllie J.C., Kaufman N. (1982) An electron microscopic study of heme uptake by rat duodenum. Lab. Invest. 47: 471-476.

Xia Y., Babitt J.L., Sidis Y., Chung R.T., Lin H.Y. (2008) Hemojuvelin regulates hepcidin expression via a selective subset of BMP ligands and receptors independently of neogenin. Blood 111: 5195-5204.

Yang Z., Philips J.D., Doty R.T., Giraudi P., Ostrow J.D., Tiribelli C., Smith A., Abkowitz J.L. (2010) Kinetics and specificity of feline leukemia virus subgroup $C$ receptor (FLVCR) export function and its dependence on hemopexin. J. Biol. Chem. 285: 28874-28882.

Yeh K.Y., Yeh M., Mims L., Glass J. (2009) Iron feeding induces ferroportin 1 and hephaestin migration and interaction in rat duodenal epithelium. Am. J. Physiol. Gastrointest. Liver Physiol. 296: G55-G65.

Zhang D.L., Hughes R.M., Ollivierre-Wilson H., Ghosh Manik C., Rouault T.A. (2009) A ferroportin transcript that lacks an iron-responsive element enables duodenal and erythroid precursor cells to evade translational repression. Cell Metab. 9: 461-473. 